WIDER Working Paper 2014/092

\title{
Regulatory reform for closing Africa's competitiveness gap
}

Ioannis N. Kessides*

June 2014 
Abstract: Over the past decade, Africa has been experiencing an economic resurgence. Yet, the continent is facing several difficult challenges and many economies of the region continue to be among the least competitive in the world. Africa's competitiveness is adversely affected by: (i) poor regional infrastructure networks; and (ii) weak institutional capacity. Increased regionalization could potentially address both these challenges. Regional integration of regulation, combined with regionalization of regulated firms, could assist the countries of Africa in overcoming national limits in technical expertise, enhance national capacity to make credible policy commitments, improve the efficiency of infrastructure industries, and increase infrastructure investment.

Keywords: regional integration, regulatory reform, competitiveness, Africa

JEL classification: F15, L51, L98, O55

\footnotetext{
*Yale University, ioannis.kessides@yale.edu

This paper was prepared for the 'Oxford Handbook of Africa and Economics' authors' conference in Beijing, 8-10 December 2013, implemented with UNU-WIDER.

Copyright (C) UNU-WIDER 2014

ISSN 1798-7237 ISBN 978-92-9230-813-1

Typescript prepared by Lesley Ellen for UNU-WIDER.

UNU-WIDER gratefully acknowledges the financial contributions to the research programme from the governments of Denmark, Finland, Sweden, and the United Kingdom.

The World Institute for Development Economics Research (WIDER) was established by the United Nations University (UNU) as its first research and training centre and started work in Helsinki, Finland in 1985. The Institute undertakes applied research and policy analysis on structural changes affecting the developing and transitional economies, provides a forum for the advocacy of policies leading to robust, equitable and environmentally sustainable growth, and promotes capacity strengthening and training in the field of economic and social policy-making. Work is carried out by staff researchers and visiting scholars in Helsinki and through networks of collaborating scholars and institutions around the world.
}

UNU-WIDER, Katajanokanlaituri 6 B, 00160 Helsinki, Finland, wider.unu.edu

The views expressed in this publication are those of the author(s). Publication does not imply endorsement by the Institute or the United Nations University, nor by the programme/project sponsors, of any of the views expressed. 
Over the past decade, Africa has been experiencing an economic resurgence. Despite the global economic crisis, Africa's gross domestic product (GDP) has been growing rapidly, on average almost 5 per cent a year since 2000 - second only to developing Asia. Medium-term growth is expected to remain robust, on the heels of a global economic recovery, the prospect of continuing high commodity prices, and investment in productive capacity (Devarajan and Fengler 2013).

Although this period of impressive growth has given rise to increased optimism about Africa's economic prospects, some serious challenges remain. Many African economies continue to figure among the least competitive in the Global Competitiveness Index (GCI)-14 out of the 20 lowest-ranked economies are African. And, overall, the continent's high growth rates have not yet translated into the rapidly improving living standards that have been seen in other regions with a similar growth performance. Low and falling productivity figures are at the core of these differences in living standards (World Bank 2013a).

Africa must make significant progress in many areas in order to enhance its productivity and set itself on a sustainable high-growth trajectory. The continent's gap with comparable regionssuch as, South East Asia, Latin America, and the Caribbean-is particularly large in two of the basic building blocks of a competitive economy: governance and institutions, and infrastructure. Beyond these gaps, many of the countries in the region also suffer from small market sizes.

International experience provides a clear measure of the huge upside potential in net economic benefits that competition, liberated from unnecessary regulatory interference, can produce in an increasing number of circumstances. Estimates of these benefits can serve as useful guideposts for the countries in Africa that are contemplating regulatory reform policies. Indeed, by unleashing market forces of competition, regulatory reform, and deregulation can make a substantive contribution towards resolving the continent's productivity and competitiveness dilemmas. However, in individual countries regulatory reform, especially when debated one issue at a time, is often blocked by well-organized interest groups that are trying to preserve their status quo benefits.

Network utilities provide crucial services for manufacturing and commerce, and so significantly influence the growth in national production. Thus economic development depends on such infrastructure-and failure to reform and modernize it undermines national competitiveness and risks economic stagnation. By some estimates, infrastructural shortcomings may be depressing firm-level productivity by 40 per cent in some parts of Africa, and investment in infrastructure can potentially boost growth rates in the region by two percentage points (Deutsche Bank 2013).

Continued investment in infrastructure will be critical to maintaining and strengthening growth over the medium term. Given the public sector's constrained fiscal space in Africa, the private sector will have to play an increasingly important complementary role in providing the substantial resources needed for improving national and cross-border infrastructure. However, owing to their long histories of arbitrary administrative intervention and political instability, the region's governments continue to have limited capacity to make credible commitments that they will not engage in political expropriation of the sunk investments made by private utilities and investors. Consequently, investors will demand high-risk premia and under-invest. 
Thus, Africa's business environment remains challenging in terms of infrastructure and institutions. Increased regionalization could potentially address both of these challenges. In addition to being an important stepping stone for building economies of scale and fostering economic diversification, regionalization can effectively elevate the domestic political debate about regulatory reform from narrow domestic issues to matters of regional economic cooperation. From a political perspective, making regulatory reform a regional issue is highly desirable. If the regulatory reform debate is elevated to a matter of regional policy that encompasses numerous reform issues, broader attention and participation from all regional interests is more likely, thereby reducing the ability of a single domestic group to block reform. Thus, regionalization of regulatory policy could mitigate the problem of regulatory capture, facilitate regulatory reform, enhance the capacity of national governments to make credible policy commitment, and, through the pooling of resources, help them overcome technical capacity constraints and establish more effective and credible regional institutions (Kessides et al. 2010).

For these reasons the framework for regional economic integration in several parts of the African continent includes co-ordination of policies in core infrastructure industries such as transport, telecommunications, and electricity. Infrastructure development is included in many regional treaties to provide the framework for aligning sector policies, designing regional master plans, developing a portfolio of synergistic projects, harmonizing regulatory regimes and investment codes, and mobilizing investment resources. Increasingly, the African nations have been moving away from integration strategies that are based solely on formal trade agreements and towards strategies that include at least some integration of infrastructure policies.

\section{$2 \quad$ Africa's competitiveness gap and regulatory burden}

Many African countries continue to be among the least competitive economies in the world. In the GCI, 14 out of the 20 lowest-ranked economies are African. The region's competitiveness as a whole trails South East Asia, Latin America, and the Caribbean. However, Africa has not remained stagnant. The region has been improving its competitiveness, although the change has been gradual and modest. Some of Africa's biggest and stubbornly persisting gaps are seen in the quality of institutions/regulatory governance, and infrastructure (World Bank 2013a).

In view of the important reciprocal relationships between infrastructure (soft-institutional and hard-physical) and regional economic integration, and their potential impacts on productivity and growth, the continent's persistent institutional and infrastructure deficiencies are worrisomeespecially at a time of rising global economic uncertainty. Thus, despite the acceleration in the continent's growth during the past decade, serious concerns remain as to how sustainable this African renaissance will be over the longer term. Reducing the competitiveness divide between African economies and other, more advanced regions will be critical for placing the region on a firmly sustainable growth and development path. The pertinent question is whether policy makers are putting into place the fundamental microeconomic reforms that are indispensable preconditions for boosting productivity and competitiveness. One of the key priorities is to maintain the momentum for regulatory reform. Specific priority areas include cutting administrative delays, removing the regulatory impediments to entrepreneurial activity, harmonizing regulations across regional markets, and improving the effectiveness of infrastructure's regulatory governance.

In terms of ease of doing business, regulations have improved in Africa in recent years. Indeed, the continent continues to record a large number of reforms aimed at easing the regulatory burden on local entrepreneurs and building stronger institutions - the majority (29 out of 33) of 
sub-indicators that are used by the World Bank to estimate the ease of doing business have improved between 2005 and 2012. In 2005 only a third of countries in the region were reforming; now over two-thirds are (The Economist 2012). During 2012-13, over 73 regulatory reforms were adopted (Figure 1). Progress in some countries has been truly impressive, with four countries in sub-Saharan Africa having been among the ten top global reformers over the last five years. ${ }^{1}$ And out of the 20 economies that have most improved business regulation since 2009, nine are in the region: Benin, Burundi, Côte d'Ivoire, Guinea, Guinea-Bissau, Liberia, Rwanda, Sierra Leone, and Togo (World Bank 2013b). ${ }^{2}$

Figure 1: Reforms reducing regulatory complexity and cost in 2012-13

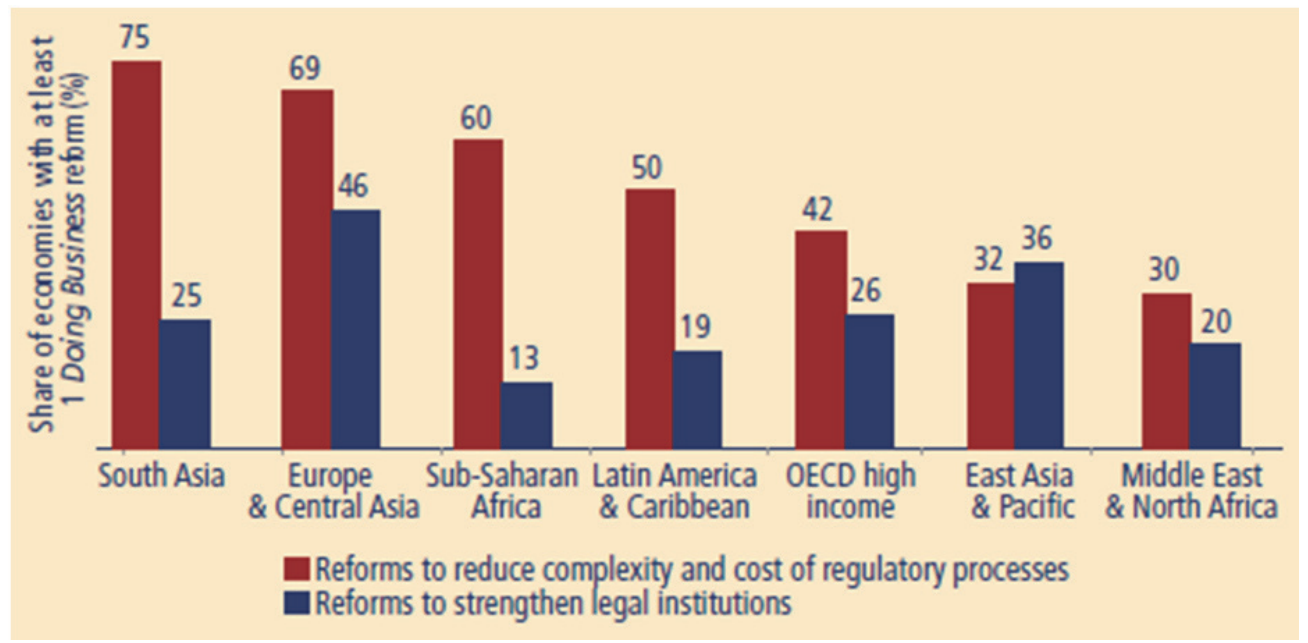

Source: World Bank (2013b).

Over the past five years sub-Saharan Africa reduced the gap with the frontier in regulatory practice by three times as much as Organisation for Economic Cooperation and Development (OECD) high income economies. All this progress notwithstanding, Africa remains the region with the lowest comparative ranking on the quality of its regulatory environment (Figure 2). The region's economies are furthest from the frontier than those of any other region in six of the ten areas measured by Doing Business. Clearly more needs to be done because entrepreneurs in Africa still face a burdensome regulatory environment.

Business regulatory reform is of particular significance in the low-income economies of the African continent. A variety of studies have detected a negative correlation between economic growth and regulatory intensity - countries with less regulation tend to exhibit higher growth in output per person (Guasch and Spiller 1999). There is also a link between better business regulations and economic growth. Thus, both the intensity and quality of regulation have important implications for economic growth. Moreover, recent research shows that economic growth remains the most important factor in determining the pace of income growth for poor people (Dollar et al. 2013). Together, this evidence seems to indicate that an effective

\footnotetext{
1 In the past five years, for example, sub-Saharan Africa accounted for 22 out of the 66 reforms recorded by Doing Business that made it easier to enforce contracts. Some economies in the region overhauled the organization of their courts or systems of judicial case management for commercial dispute resolution. However, the main trend has been to introduce specialized commercial courts that led to greater specialization of judges - resulting in faster resolution times, cheaper contract enforcement, shorter court backlogs, and increased efficiency (World Bank 2013b).
}

2 Of these, Rwanda has made the most progress overall. The country has embarked on an ambitious programme of regulatory and administrative reform explicitly designed to improve the climate for business. In just over five years, Rwanda climbed from the 150th position to 32nd in the ease of doing business ranking of the World Bank's Doing Business (Ernst \& Young 2013). 
programme of regulatory reform and deregulation has the potential to make a significant contribution towards reducing poverty and boosting shared economic prosperity in the African continent.

Figure 2: Ease of doing business around the world (2013)

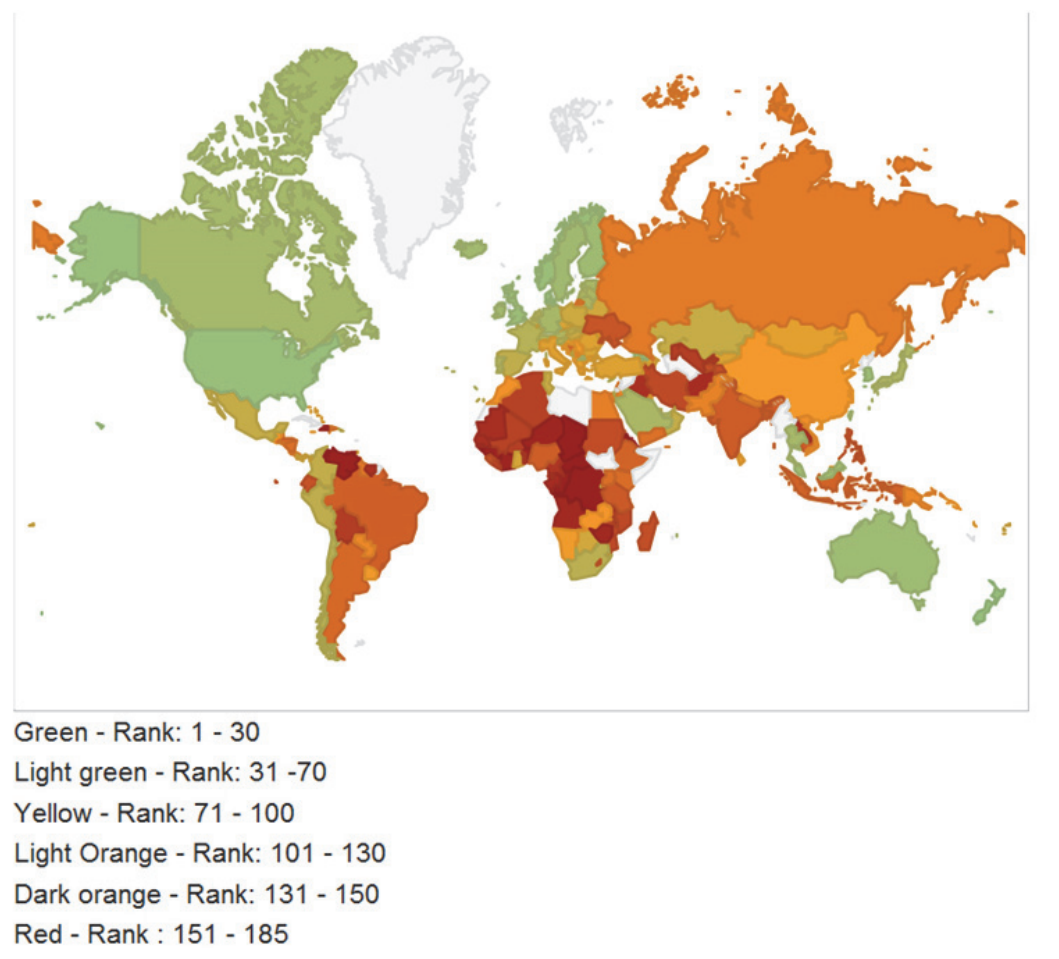

Source: Global Finance (2013). Copyright @ 2014 Global Finance Magazine; figure reproduced here for noncommercial purposes.

The global regulatory reform movement

Over the past two decades, substantive steps towards total deregulation of some markets and less comprehensive regulation of others have been taken in many countries around the world. While the most dramatic manifestations of this deregulation revolution have been in industries with competitive market structures, a major reassessment of regulatory policy in industries with natural monopoly (or tightly oligopolistic) characteristics has also taken place. The main impetus for regulatory decontrol was provided by the increasing recognition that government intrusion into pricing, investment, and other such business decisions imposes substantial economic costs-it can discourage investment in innovation, shelter inefficiency, promote misallocation of resources, cause incentive breakdowns, and reduce the price and quality options that the public would be offered under unfettered market allocation. In addition, technological change and regulatory experience facilitated the formulation of policy which permits a much greater toleration of factors that make for natural monopoly while at the same time lessening the need for public intervention.

Regulatory experience and new bodies of economic analysis underpinned the view that: where public measures are called for, the types of market intervention that ought to be undertaken are, in many cases, significantly different from those that have been traditionally employed; and that there are some cases in which public intervention is inappropriate even though it was previously thought to be necessary. Indeed, recent policy developments call for a major reorientation of the traditional regulatory rules and procedures, and offer two types of guidance to regulators. First, 
they provide an improved set of criteria distinguishing between those cases in which intervention by the public sector is warranted and those in which it is not. Second, they establish an improved set of guidelines for appropriate government intervention in the structure and conduct of firms in those cases in which intervention is called for, i.e. they offer more effective tools to the regulators that increase the public welfare effects of intervention. In several countries, innovative methods of regulation have already been introduced and major sectors of their economies have undergone far reaching regulatory reform.

The experience from the economies that have implemented substantive regulatory reforms confirms what theory predicts: decentralized market-oriented decision-making that is freed from unnecessary regulatory control and that is energized by market incentives is the surest means of finding and implementing innovative solutions to problems posed in several sectors of the economy. As a consequence of deregulation, there have been fundamental changes in the way in which firms in these countries are conducting business. By and large, these changes reflect efficiency-enhancing structural reorganization and increasing diversity in price-service options, and greater responsiveness to consumer demands as well as to marketplace opportunities for innovation. The removal of significant impediments to entry and market access has resulted in new opportunities for small entrepreneurial firms and start-ups, more innovation by larger entrepreneurial corporations, the consequent introduction of new products and services, and more responsive to consumer demands.

While most firms were quite successful in absorbing the shock of deregulation and operating in a competitive environment, others experienced difficulties of adjustment, and major restructuring of their respective industries occurred. Indeed, one of the necessary consequences of regulatory reform is that there must be a possibility that relatively inefficient firms will lose profitability and go into liquidation. Moreover, the post-deregulation period has been characterized by pressures to reduce pay scales towards those in the unregulated economic sectors and to increase productivity through more efficient use of labour. Inevitably, these changes led to some labour displacement. These dangers, of course, are the natural concomitant of a freer competitive environment. Still, the available evidence indicates that, on average, regulatory reform and deregulation have yielded very positive results for both producers and consumers (Kahn 2004; Rose 2013).

\section{Regulatory reform for enhancing Africa's competitiveness}

Regulatory reform improves the efficiency of a nation's economy, enhances its ability to adapt to change, and strengthens its international competitiveness. 3 It unleashes market forces of competition thereby providing powerful incentives for firms to become cost-effective and innovative, to realign prices with resource costs, and to improve the quality of their products and services. Yet, in many African countries there appears to be a strong countervailing reluctance to spin activities out of direct public control and to deregulate economic activity. This reluctance can be linked to both protection of status quo benefits and to concerns over the transitional

\footnotetext{
3 As Noll (1997) points out, as trade barriers fell, regulation became a more significant factor in affecting the relative prices of exports, imports, and domestic production. And regulatory reform began to be perceived as a means by which a nation could capture greater benefits from trade liberalization. This is because inefficient domestic regulations can cause otherwise efficient firms to lose sales to less efficient sources of supply from countries with better/less burdensome regulatory systems. For example, inefficient border administration reduces the price competitiveness of African exports in global markets and adds to the cost of imports. The transport and communications infrastructure is far less developed than in other regions, which also significantly raises the cost of trading, particularly for landlocked economies.
} 
problems of deregulation, especially those related to labour entrenchment, tariff rebalancing (and the consequent price increases for certain formerly subsidized services), business liquidation, and universal service. Governments do not easily and willingly forgo using the instruments they have in hand for the collection and disbursement of political benefits.

The African continent has a potential for substantial gains from microeconomic and regulatory reform as key sectors of the region's economies remain heavily regulated. However, there are adverse conditions that render the process of such reform somewhat delicate. In view of the delicate macroeconomic condition of some of the continent's economies, their imperfectly developed capital markets, and their generally weak economic institutions, caution is appropriate with respect to regulatory decontrol. For example, major price revisions are likely to be disruptive and, in some instances, greatly complicated by high rates of inflation.

Determining the full consequences of any regulatory reform is virtually an impossible task. The relaxation of the present constraints upon the operations of national firms will generate opportunities for improvements in the region's economies. But, it will also engender risks and uncertainties which could adversely affect the general welfare. There are also substantial dangers involved in failing to move in the direction of greater reliance on competitive market forces that are freed from unnecessary regulatory controls. The cross-country experience reveals that wellintentioned regulatory controls caused enormous distortions in productivity and in service. Indeed, there is strong evidence from Africa that governmental intrusion into pricing, investment, and other such business decisions has induced substantial inefficiencies and imposed heavy social costs.

All of the above considerations - the difficulties of continuing under the present regulatory regime and the potential, mainly transitional hardships under a more competitive system-lead to policy recommendations that envision an orderly transition to a goal of substantial deregulation of the African economies. The purpose is to implement policy changes that achieve the benefits of deregulation-more efficient industries that are better attuned to the needs of consumers and other users of their services-without threatening the immediate extinction of individual firms or the rapid destabilization of key sectors of the economy.

\section{Regionalization for more effective regulatory governance}

Africa is facing a significant challenge in accelerating and broadening 'enabling environment' reforms to stimulate economic growth, generate employment, and enhance economic prosperity. Outdated, duplicative, and unnecessary administrative procedures and other regulations impose substantial efficiency costs on the region's economies, promote corruption, and are needlessly stifling job creation and undermining sustained economic growth. Yet reviewing, assessing, and repealing thousands of rules, administrative procedures, and regulations across many ministries, government agencies, regulatory bodies, and levels of government, is a hugely challenging task. It can also entail significant political costs and can be strenuously resisted by well-organized interest groups whose status quo benefits are threatened by such reforms. Indeed, regulatory and administrative reforms when debated one issue at a time can be effectively blocked by special interest groups.

A broad, systemic, and regionally co-ordinated approach is needed to significantly reduce the administrative burdens that regulation imposes on productive business activity in Africa. Moreover, in view of the enormous pressures and great sense of urgency generated by the continent's continuing competitiveness challenges, there is a need for more rapid and comprehensive microeconomic reforms that will produce faster and sustained benefits for the 
region's economies. In designing such regulatory reform strategies, Africa can benefit from the implementation experience of other countries that have successfully streamlined regulations, constraining investment and employment growth.

The guillotine strategy (pioneered by Sweden in the 1980s), for example, entails a systematic and transparent approach to rapidly reviewing a large number of regulations and eliminating those that are outdated without the need for lengthy and cumbersome legal action on each specific rule. It facilitates a rapid and effective response to fixing unneeded and inefficient regulation. It can also contribute to establishing a sustainable framework for quality control of new business regulations to avoid re-occurrence of the same problems (so-called creeping re-regulation). It can substantially reduce the costs of reform within political and legislative systems that are already overburdened with difficult reform challenges (Jacobs and Astrakhan 2006).

\section{Regionalizing regulation to mitigate representation bias and facilitate commitment 4}

An important advantage of regionalizing regulatory reform is that it can be used to elevate the domestic political debate about regulation from narrow particularistic issues to matters of national economic performance and regional economic co-operation or integration. From a political perspective, making regulatory reform a regional issue is highly desirable. A common political barrier to domestic regulatory reform is that, if reform is perceived as a domestic matter and debated one issue at a time, well-organized special interests are more likely to have the political power to block it. For most specific regulatory issues, the beneficiaries of reform are numerous, but their per capita benefits are frequently too low or indirect to generate significant political pressure for reform. If the reform debate is elevated to a matter of regional policy that encompasses numerous reform issues, broader attention and participation from all interests is more likely, thereby reducing the ability of a single group to block reform.

A useful analogy is to the process of setting tariffs. When each nation independently sets each tariff, the outcome is likely to be tariffs that are higher than the tariffs that would be negotiated bilaterally as part of a comprehensive regional trade agreement. The reason is that debating tariffs one product at a time maximizes the opportunity for organized interests with a direct stake in a policy to be unduly influential. If a tariff on a specific product is under review, the domestic industry that produces the product is likely to be intensely interested to exercise whatever political influence it has to obtain a policy decision favourable to itself. However, because the final price of the product is less important to each buyer than to each producer, the former are less likely to participate in the debate. Consequently, each important domestic industry may receive and preserve a tariff or a favourable regulation when policy is debated in a purely domestic context one industry at a time, but receive neither protective tariffs nor protective regulation when policy is developed regionally and covers many industries.

When each regulation is considered separately as a matter of domestic concern within a specialized agency, the government is likely to be under less pressure to adopt an efficient policy. If a regulation imposes unnecessary costs uniformly on firms in a domestic industry, sales of the industry's product may be suppressed somewhat by higher prices, but the individual firms are unlikely to suffer very much because none is being disadvantaged relative to a competitor. If regional/international trade threatens the industry, however, the industry will energetically seek relief. The politically expedient response may be to inhibit trade competition, either by using

4 This section is based on Roger Noll's numerous contributions in this area. 
regulation as an indirect trade barrier or by banning trade while invoking a rhetorical attack on the lax standards of a trading partner. This approach placates the regulated industry and the other interests that place high value on the regulatory policy. The primary organized interest that is harmed, that of foreign producers, is more easily ignored because they do not participate in domestic politics.

Just as simultaneous negotiations over tariffs on all products facilitate reaching agreements that provide freer trade, so too simultaneous negotiations of numerous areas of regulation facilitate eliminating indirect trade barriers. As with tariffs, the inclusion of multiple regulatory policies within the same negotiation creates more opportunities and more mutually beneficial bargains to reduce distortions simultaneously on all fronts. Thus, the incorporation of regulation into regional trade agreements should follow the same principles that have been generally followed with respect to tariffs and quotas. Specifically, if regulatory policy is part of a regional/international agreement, it must reduce, not increase, distortions in the regional/international economy and extend, not contract, the extent of liberalization. Introducing regulation into single-product negotiations is prone to lead to increased trade distortions (by using regulation to inhibit trade). In particular, negotiations about a single product or area of regulation run the risk of creating an alliance between protectionists and the most ardent advocates of a particular regulatory policy who seek regulations that go far beyond those that maximize net social benefits.

The same argument applies to the enforcement of agreements not to adopt anti-competitive regulations, if enforcement powers reside solely in domestic agencies. Domestic producers are likely to be more effectively represented than foreigners in the agency and the background political system in which the agency must operate. And domestic regulatory agencies are frequently willing to sacrifice competition as well as some of the effectiveness of regulatory policies in order to advantage domestic producers. Regional institutions for resolving regulatory issues, on the other hand, operate in a more balanced political environment. These institutions can be a means through which nations mutually can commit to maintain pro-competitive regulatory reforms.

For these reasons, regionalization/internationalization of regulatory reform can succeed by enfranchising foreign producers in domestic regulatory policy across a spectrum of industries. In the context of a dispute about the trade effects of a particular regulation, intervention by an international organization frequently is met with cries of outrage-an intervention by foreigners into domestic policy. All international agreements entail some loss of the ability to act independently in order to achieve something else of value, which in this case is a worldwide regulatory system that is more efficient and freer of trade distortions. Such an institution generates net economic benefits to each country, even if some cases create domestic losers. The creation of institutions for enforcing agreements to eliminate indirect trade barriers is a means to balance the political influence of these domestic losers.

\section{$7 \quad$ Regionalizing regulation to enhance policy credibility and commitment}

Services delivered by infrastructure industries are economically and politically important. Because of their importance and ubiquitous consumption, the prices of infrastructure services typically are scrutinized by interest groups and even the general public, and so receive considerable political attention. These characteristics can motivate governments to behave opportunistically vis-à-vis privatized utilities. A large portion of infrastructure costs are fixed and sunk-i.e. once the investment is made the assets cannot be re-deployed elsewhere. Thus, utilities are vulnerable to administrative expropriation of their sunk investments. 
Given the public sector's constrained fiscal space in most African countries, the private sector will have to play an increasingly important complementary role in providing the substantial resources needed for improving regional connectivity through national and cross-border infrastructure investment. However, private utilities and investors that are vulnerable to administrative intervention in Africa can be expected to demand high-risk premia and to underinvest in infrastructure unless the region's governments are able to make a credible commitment not to expropriate sunk investments. Owing to their long histories of arbitrary administrative intervention and political instability, these governments have a very limited capacity to make such credible commitments.

Regionalization of regulation creates institutions whose policies and decisions can be changed only by mutual agreement among several nations. Consequently, political change or government opportunism in one country is insufficient to cause a radical change in regulatory governance unless the government is willing to sacrifice all of the other benefits that arise from regional economic co-operation. Thus, regionalization of regulation could enhance the ability of the governments in Africa to credibly commit to a stable regulatory process.

\section{$8 \quad$ Regionalization to overcome technical capacity constraints}

Effective regulation, especially in key infrastructure sectors of the economy, requires professional staffs that are expert in the relevant economic, accounting, engineering, and legal principles and familiar with good regulatory practice elsewhere. These types of specialized skills are also needed in the regulated firms. Therefore, the question arises whether some of the poor, and especially small African countries, would have a sufficient supply of specialists to staff their regulatory agencies, run their utilities, and provide for policy capacity within the relevant sectoral ministries.

The principal difficulty is not in finding a few competent regulatory commissioners. All that is required of an agency's commissioners is to be at least somewhat familiar with the broad regulatory issues and to have some relevant expertise. Commissioners do not need to be up-todate economic or technical experts. Instead, the more challenging task is to find the necessary expertise for the agency's staff, which performs economic and technical policy analysis and provides institutional continuity for the development and responsiveness of the regulatory system (Stern 2000). The number of technical staff that is necessary to regulate infrastructure industries is very large, and in small, poor nations the number of people with the requisite expertise can be quite small. By pooling resources among nations, regional regulatory authorities alleviate some of the problems that arise from the scarcity of technical and economic expertise at the national level. Moreover, even in middle-income nations, national regulatory agencies can have a high fixed-cost relative to market size (Noll 2000; Stern et al. 2002). The creation of regional regulatory authorities can spread the fixed costs of regulation among the larger population of a regional economic community.

\section{Spectrum of regulatory regionalization options}

Obtaining consensus from all governments in a region for a regional regulatory authority is problematic due to different attitudes and commitments toward reform, as well as concerns about national sovereignty. It requires considerable co-operation and trust between countriesperhaps more than now exists in many parts of the world. Thus, initially regional regulatory cooperation might be a more realistic option for alleviating scarce regulatory expertise and resources. As a first step, a regional regulatory entity could be established to facilitate 
information exchange and offer non-binding advice on technical matters. But consensus for multinational/regional regulatory agencies could increase as more countries reform, gains from regional policy co-ordination and trade become more apparent, and countries (especially small ones) confront the costs and staffing challenges of creating and maintaining national regulators.

Regional harmonization is not a binary variable. It entails a wide range of policy options that lie between complete national autonomy and full integration (Figure 3). At one extreme, the members of the community surrender their sovereignty on regulatory and other policy decisions to a regional regulatory authority (RRA). At the other extreme, the national regulatory authorities (NRAs) retain full jurisdiction over all areas of regulatory policy and decision-making, with the RRA's role limited to disseminating information, issuing non-binding guidelines, and acting as a source of centralized technical expertise.

Figure 3: Regionalization models

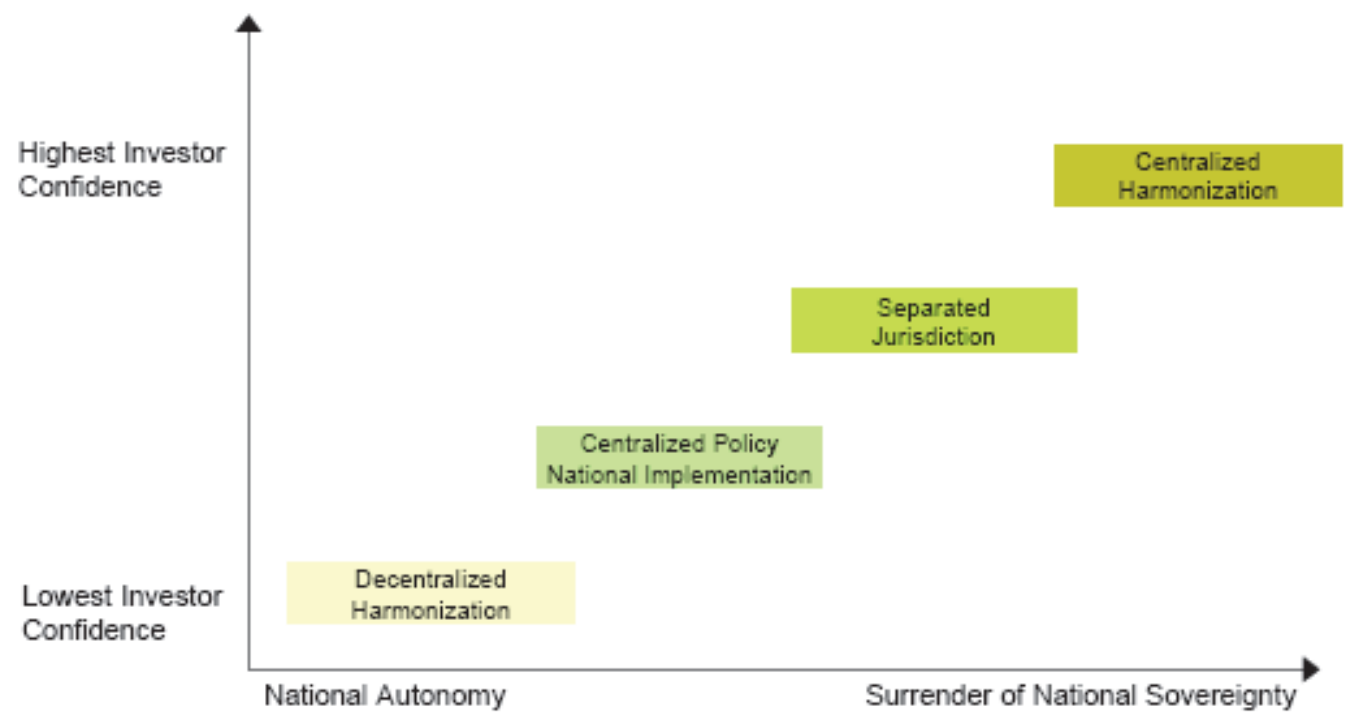

Source: Deloitte Touche Tohmatsu (2003). Copyright @ 2014 Deloitte Development LLC; figure reproduced here for non-commercial purposes.

We describe below the range of regulatory regionalization options in the telecommunications sector. 5 Clearly, the analysis can be easily extended to the other network industries.

\subsection{Centralized harmonization}

Under full, centralized harmonization, the RRA has the statutory authority to make policy determinations that are binding on the member states. Moreover, the RRA has the legal power to enforce those decisions and to impose penalties on non-complying member states. Thus, the RRA has the authority to:

- Regulate end-user prices, impose quality of service requirements on all licensed telecommunications operators in the region, and attach penalties for non-compliance;

- Regulate the terms and conditions of access to essential (bottleneck) telecommunications facilities, and intervene to resolve interconnection disputes;

- Manage and allocate the frequency spectrum in the region;

5 This section is based on Deloitte Touche Tohmatsu (2003). 
- Issue licences for all telecommunications services throughout the region;

- Pre-empt local and national rules regarding rights of way;

- Collect and disburse funds to support universal service and other social goals in the telecommunications sector;

- Represent the region in international organizations and forums.

Under centralized harmonization the NRAs have no independent policy-making authority. Instead, their role is limited to providing an input into the consultative process of the RRA, supplying data on national market conditions, and advising on implementation issues.

The centralized harmonization model treats the entire region as a single, unified economic space. Thus, it offers the greatest opportunity to exploit regional economies of scale in the telecommunications industry. It could also reduce the cost of doing business in the region by streamlining administrative processes and lowering the regulatory costs of entry (e.g. by facilitating the acquisition of licences and permits through 'one-stop shopping'). However, the establishment of a supranational regulatory authority could properly raise concerns about accountability and the need for checks and balances on the powers of such authority.

\subsection{Separated jurisdiction}

Under separated jurisdiction, the RRA has the mandate to regulate all cross-border telecommunications transactions. It also represents the region in international forums. The NRAs retain full regulatory authority over telecommunications transactions and services that do not cross national borders. This model roughly corresponds to the US system of dual-state and federal regulation over telephone service, whereby the Federal Communications Commission has jurisdiction over interstate telecommunications transactions and the state public service commissions have authority over all intrastate services.

\subsection{Centralized policy/national implementation}

Under this model, the RRA issues binding regulatory and other policy directives which are then adopted and converted into law by the member states. The NRAs have the full responsibility to implement and enforce these directives. Thus, each member state retains its sovereignty over regulatory matters but is obligated to implement its national policies in accordance with the overall policy recommendations and directives issued by the centre.

In this model, the RRA acts as a policy-making body that establishes regional policy through a consultative process. It is very similar to the one adopted by the European Union where the Commission formulates policy and issues directives that have the force of European law. But it is the responsibility of the member states to adopt the directives into national laws and regulations and thus to establish and implement national regulation.

This model treats the entire region as a single economic space while at the same time it recognizes the importance of national sovereignty and the reality of significant cross-country differences in institutional endowments and legal structures, traditions, and processes. The practical outcome of this compromise between maintaining national sovereignty and pursuing regional policy harmonization is likely to be the uneven adoption and implementation by the member states of policies developed by the regional authority. Inevitably, some member states will be slow and reluctant to implement the RRA directives into national laws and regulations. 


\subsection{Decentralized harmonization}

Under this model, the RRA acts as a central source of technical expertize, undertakes regional and benchmarking policy studies, facilitates information exchange, publishes reference papers that summarize the emerging international experience on important policy issues, and organizes regional training programmes. The RRA has no regulatory authority but can issue non-binding regulatory and other policy guidelines.

While this model, at least in the early stages of regional integration, represents the most realistic organizational option, it offers very little assurance that uniform and consistent regulatory policies will be effectively implemented across the region. Thus, trade distortions, created by differences in regulatory efficiency among the countries of the region, are likely to persist.

\section{The West African Telecommunications Regulators Association}

The Economic Community of West African States (ECOWAS) was founded on 28 May 1975, when 16 anglophone, lusophone, and francophone countries signed the Treaty of Lagos. ECOWAS is comprised of 15 countries which include: Benin, Burkina Faso, Cape Verde, Côte d'Ivoire, Gambia, Ghana, Guinea, Guinea-Bissau, Liberia, Mali, Niger, Nigeria, Senegal, Sierra Leone, and Togo. ${ }^{6}$ The primary objective of ECOWAS is to promote regional co-operation and integration and to create a unified economic space in order to facilitate economic growth and development in West Africa. The preamble to the 1975 ECOWAS treaty notes that the community was created because of the '... overriding need to accelerate, foster and encourage the economic and social development of member states in order to improve the living standards of their peoples' (Aryeetey 2001). ECOWAS saw regional integration as a multi-stage process leading to a customs union and ultimately to the establishment of an economic and monetary union that would raise the living standards of its people and enhance economic stability in the region. ${ }^{7}$ The key elements of ECOWAS' policy have been to eliminate all tariffs and other trade barriers between the member states and to establish a customs union, a unified fiscal policy, and co-ordinated regional policies in the transport, communications, energy, and other infrastructure facilities (Ajibewa 2002).

In 2002 ECOWAS created the West African Telecommunications Regulators Association (WATRA), an organization of regulators and the respective responsible government ministries of West Africa territories. WATRA's key objectives are to:

- Encourage the establishment of modern legal and regulatory structures for telecommunications service delivery in all member states of ECOWAS;

- Promote regulatory harmonization and the adoption of uniform technical and quality standards for telecommunication services and equipment;

- Encourage increased market liberalization and competition initiatives;

- Support universal access;

- Contribute, through the progressive integration of regulatory mechanisms, towards subregional market integration in the telecommunications sector;

\footnotetext{
6 In 2000, Mauritania withdrew its membership from ECOWAS.

7 Lecture by ECOWAS Executive Secretary, Mohamed Ibn Chambas: 'The ECOWAS Agenda: Promoting Good Governance and Regional Economic Integration in West Africa'.
} 
- Contribute to human resource and capacity-building efforts in emerging information and communications technologies in the sub-region.

In furtherance of these objectives WATRA may:

- Deliberate on issues relating to telecommunications regulation and make recommendations to governments of members;

- Dollaborate with other international organizations and public and private initiatives involved with the modernization of the structures for telecommunications service delivery in Africa;

- Take any other action and adopt any other measure as it may deem necessary or desirable for the achievement of its objectives.

Thus, WATRA is primarily a consultative body. It can formulate common regional policy objectives and issue non-binding guidelines to the NRAs on regulatory and technical issues. However, the member states will retain final authority over policy implementation. Thus, the institutional structure of WATRA is closest to the decentralized harmonization model (Figure 1). 8 Still, WATRA could exercise considerable influence over regional regulatory policy and make a substantive contribution towards regulatory harmonization by aggregating relevant data and case experience, facilitating cross-border benchmarking, and developing mechanisms for regional consultation and consensus building. Such consultative mechanisms could encourage the active participation of NRAs, operators, and potential investors in formulating future regulatory policies and thus assist in achieving more uniform and consistent regulatory policies at the regional level.

In September 2005, WATRA took on the leading role in approving the ECOWAS telecommunications guidelines on key regulatory issues at an ordinary general meeting in Accra.9 These guidelines formed the basis for ECOWAS Telecommunications Directives and were adopted by ECOWAS Ministers in 2006. These efforts were a first in Africa and could set an example for other sub-regions in Africa (Box 1) and around the world.

\section{The Eastern Caribbean Telecommunications Authority}

The Organization of Eastern Caribbean States (OECS) was established in 1981, when seven Eastern Caribbean countries (Antigua and Barbuda, Commonwealth of Dominica, Grenada, Montserrat, St Kitts and Nevis, St Lucia, and St Vincent, and the Grenadines) signed a treaty agreeing to co-operate with each other, promote unity, and contribute to the sustainable development of the member states through the creation of a single economic and financial space in the region. Since the founding of OECS, its member states established several subsidiary institutions to promote growth and development in the region.

The economies of the OECS were facing, during that period, the dual challenge of slowing economic growth and persistently high unemployment and poverty rates. One important characteristic of the economies in the region was their heavy dependence on agriculture.

8 The statutes of ECOWAS' founding treaty require its member states to adopt and implement community policy objectives and directives into their national legislation. However, ECOWAS presently lacks the authority to enforce compliance. Thus, the intent of the ECOWAS treaty was to adopt the Centralized Policy/National Implementation harmonization model.

9 For full text see http://www.itu.int/newsroom/press_releases/2005/12.html 
Regional economic dynamism was affected by reduced preferential market access for traditional crop exports, stiffer competition from other tourism destinations, and growing macroeconomic instability. The region urgently needed to identify and carve out new areas of competitive advantage in the global economy and to create a more stable and less vulnerable platform for economic development and poverty reduction. Thus, regional leaders recognized the need to diversify their economies and place greater emphasis on services. However, inefficient telecommunications services were seen as posing a serious obstacle to such a regional economic transformation. The telecommunications sector in the region was characterized by monopoly control, high costs and low service quality, limited access to technology and telecommunications infrastructure, and shortage of skilled personnel.

Box 1: Other African regionalization initiatives

Economic community: South African Development Community (SADC).

Member states: Angola, Botswana, Democratic Republic of the Congo, Lesotho, Malawi, Mauritius, Mozambique, Namibia, Seychelles, South Africa, Swaziland, Tanzania, Zambia, and Zimbabwe.

Related telecommunications association: Communications Regulators Association of Southern Africa (CRASA).

Economic community: Common Market for Eastern and Southern African (COMESA).

Member states: Burundi, Comoros, Democratic Republic of Congo, Djibouti, Egypt, Eritrea, Ethiopia, Kenya, Libya, Madagascar, Malawi, Mauritius, Rwanda, Seychelles, Sudan, Swaziland, Uganda, Zambia, and Zimbabwe.

Related telecommunications association: Association of Regulators of Information and Communication in Central and Eastern Africa (ARICEA).

Economic community: Central African Economic and Monetary Community (CEMAC) and Economic Community of Central African States (CEEAC).

CEMAC Member states: Cameroon, the Central African Republic, Chad, Democratic Republic of the Congo, Equatorial Guinea, and Gabon.

CEEAC Member states: Angola, Burundi, Cameroon, Chad, Central African Republic, Gabon, Republic of Congo, Democratic Republic of the Congo, Equatorial Guinea, Rwanda, Sao Tome and Principe.

Related telecommunications association: Central African Telecommunication Regulators Association (ARTAC).

Source: Based on InfoDev/ITU (2006).

In 1998, five members of OECS, Dominica, St Kitts and Nevis, Grenada, St Lucia, and St Vincent, signed an agreement establishing a common regulatory framework for their telecommunications sectors. This agreement signified a strong commitment by these member states to a comprehensive telecommunications reform agenda that included extensive measures of liberalization and the renegotiation of Cable \& Wireless' exclusive licence to provide 
telecommunications services in their territories. 10 The exclusivity clauses in Cable \& Wireless' licence were deemed outdated and injurious to the economic development of the member states because they prohibited the entry of competitors offering innovative services that exploited the revolutionary changes in telecommunications technology. Moreover, Cable \& Wireless, which was guaranteed a 15 per cent rate of return on all of its investments, had no obligation to pursue universal service goals.

To facilitate the harmonization of their telecommunications regulatory frameworks, the five member states signed a treaty in 2000 creating a regional regulatory body. The Eastern Caribbean Telecommunications Authority (ECTEL) - the first regional telecommunications regulatory authority in the world - was established to provide advice and make recommendations on telecommunications matters and help manage the sector in the member states. At the state level, National Telecommunications Regulatory Commissions (NTRCs) remained responsible for the implementation of regulations and policies with technical assistance from ECTEL. Thus, the NTRCs were to monitor and enforce regulations, manage the licensing process, collect all fees (licences and use of spectrum), engage in dispute resolution, inspect and certify customer premise equipment and wiring, and monitor and report on spectrum use and interference.

The primary substantive function of ECTEL was to co-ordinate a regional reform agenda and facilitate the liberalization of the telecommunications sector by designing a transparent, objective, competitive, and investor-friendly licensing and regulatory regime. Thus, its key objectives were to promote:

- Open entry, market liberalization, and competition in telecommunications of the contracting states;

- Harmonized policies on a regional level for telecommunications of the contracting states;

- Universal service, so as to ensure the widest possible access to telecommunications at an affordable rate by the people of the contracting states and to enable the contracting states to share in the freedom to communicate over an efficient and modern telecommunications network;

- An objective and harmonized regulatory regime in telecommunications of the contracting states;

- Fair pricing and the use of cost-based pricing methods by telecommunications providers in the contracting states;

- Fair competition practices by discouraging anti-competitive practices by telecommunications providers in the contracting states;

- The introduction of advanced telecommunications technologies and an increased range of services in the contracting states;

- Increased penetration of telecommunications in the contracting states;

- The overall development of telecommunications in the contracting states.

The results of the region's unified telecommunications reform agenda were quite impressive. Competition expanded considerably after the monopoly rights of Cable \& Wireless were terminated in 2001. By the end of 2004, close to 40 licences had been issued to new entrants in the ECTEL member states for fixed public, mobile, and internet networks and services. The regional cellular penetration ratio increased from 2.3 per cent in 2000 to an estimated 63 per cent by the first quarter of 2004. Significant growth also occurred in other services including fixed and

10 In St Lucia, the exclusive licence of Cable \& Wireless was to expire in 2000. However, in the case of St Kitts and Nevis, the exclusivity period extended to 2024. 
internet services. Competitive entry predictably exerted a strong downward pressure on the price of most telecommunications services. The average prices for calls from the region to the US were reduced by more than 70 per cent between the start of liberalization and 2004. For example, in St Vincent and the Grenadines, tariffs to the US dropped from EC $\$ 4.90$ to EC $\$ 1.65$, while domestic tariffs fell from East Caribbean dollar EC $\$ 0.17$ to EC $\$ 0.09$ per minute. These tariff changes led to significant net savings and surplus to consumers estimated at EC $\$ 9.5$ million per year over the 1998-2003 period for St Vincent and the Grenadines. The ECTEL-wide benefits were estimated at EC $\$ 54$ million per year, in the fixed line segment alone (USAID/CARANA 2004).

\section{Effective regulation for seamless infrastructure and greater connectivity}

Africa has substantial human and natural resources. The forces of globalization could potentially have a major transformational impact on the region's role in the world economy. Modern and sophisticated production networks would allow the continent to energetically exploit the opportunities offered by globalization and, in consequence, to experience sustained economic growth and prosperity. And yet Africa's potential remains largely untapped and it still plays a relatively minor role in global economic activity in part due to insufficient region-wide connectivity. Many parts of Africa with vast resources and a huge number of communities remain economically as well as geographically isolated.

One of Africa's greatest assets is its enormous cultural and physical diversity. However, without good connectivity, diversity can lead to conflict and disparity rather than to economic prosperity. Efficient, fast, reliable, reasonably priced, and seamless infrastructure connections are indispensable for the effective exploitation of natural resource and production complementarities, and the free flow of goods and services across the entire region. Thus they are crucial for improving the region's productivity and trade competitiveness. Unfortunately, most African countries have inadequate infrastructure, characterized by low service quality, high prices (twice as expensive as elsewhere), and missing regional links. Africa's road density-an indicator of connectivity within countries-is substantially lower than in other developing regions: 204 kilometres of road per 1,000 square kilometres with only one-quarter paved, compared to a global average of 944 kilometres per 1,000 square kilometres, with more than one-half paved. Similarly, the spatial density of the continent's rail networks is low and 13 countries have no operating railway at all. Moreover, most of Africa's major ports suffer from significant capacity constraints and low operating efficiencies. And only one-fifth of the continent's population has access to electricity as compared to one-half in South Asia and more than four-fifths in Latin America. More than 30 African countries are experiencing power shortages and regular interruptions in service, and the cost of generating electricity is exceptionally high and rising (Foster and Briceno-Garmendia 2010).

The resumption of economic growth in recent years has exerted significant pressure on Africa's existing infrastructure networks and is rapidly unmasking a long list of supply-side infrastructure constraints and bottlenecks: poor road and rail networks with important missing links and significant operational capacity problems; congested and inefficient regional ports; inadequate electricity supply; and poor access to information and telecommunications technology. The elimination of these supply-side constraints will require significant amounts of infrastructure investment. The countries in the region do not have the resources to provide the necessary financing from general revenues. Moreover, an investment plan of this magnitude cannot be undertaken by the private sector alone. It will require creative partnerships between the public and private sectors. It will also require effective regulatory governance that is presently lacking. 
An important reciprocal relationship exists between infrastructure and economic integration. Cross-border infrastructure facilitates physical connectivity which is essential for enhanced regional co-operation and economic integration. Indeed, the key driving forces behind the recent wave of globalization are lower barriers to trade and investment, and lower transportation and communication costs. Major efficiency improvements in transportation and the application of modern information and communication technologies have facilitated the geographic division of production processes. A much larger number of geographically dispersed production units can participate, contributing to the value added chain according to their comparative advantage. Thus, the opportunities of individual economies to participate in international production networks have been broadened considerably (Kuroda 2006; ESCAP 2007).

The development of regional markets, in turn, creates interdependencies that increase the demand for infrastructure. After all, infrastructure networks are the conduits for these flows. Transportation infrastructure is at the heart of regional integration. Traded goods flow through roads, railways, inland waterways, ports, and airports, as do people seeking to take advantage of attractive services or job opportunities in other nations. Therefore, an efficient and integrated transport system facilitates trade and factor mobility. An integrated communications system also can spur the growth of trade as well as reduce costs by enhancing the accessibility and affordability of information, facilitating long-distance transactions, and linking the region with the rest of the world. Not surprisingly, limited development of transport, communications, and energy networks is one of the most frequently cited obstacles to cross-border trade and investment and ultimately to connectivity in many regions of the world (African Development Bank 2006).

Whereas infrastructure has long been recognized as having a crucial role in facilitating economic integration, some ancillary propositions are not widely recognized. First, greater welfare gains can be realized through deeper forms of regional integration that entail harmonization of legal, regulatory, and institutional frameworks. Second, reforms that reduce cross-border transaction costs and improve the performance of backbone infrastructure services are arguably more important for the creation of an open, unified regional economic space than trade policy reforms narrowly defined. Third, all economies benefit from the more rational use of resources that arises from co-ordination of regional infrastructure development.

For these reasons the framework for regional economic integration in several parts of the world includes co-ordination of policies in core infrastructure industries such as transport, telecommunications, and electricity. Infrastructure development is included in many regional treaties to provide the framework for aligning sector policies, designing regional master plans, developing a portfolio of synergistic projects, harmonizing regulatory regimes and investment codes, and mobilizing investment resources. Increasingly, nations are moving away from integration strategies that are based solely on formal trade agreements and towards strategies that include at least some integration of infrastructure policies (Moreira 2007).

The creation of a seamless infrastructure to enhance connectivity has two components: 'hard' or physical infrastructure (i.e. long-term technical structures, equipment, and facilities-roads, water supply, power grids, telecommunications networks, railroads, ports, airports, and so forth); and 'soft' infrastructure (i.e. regulatory mechanisms and other institutional frameworks, and substantive policies that must be put in place to facilitate the efficient operation and functioning of the hard component). Even greater connectivity and associated welfare gains could be realized with deeper forms of regional co-operation in infrastructure which are not limited to just linking physical networks but also include the harmonization of legal, regulatory, and institutional frameworks. Disparities of regulatory treatment across borders in the region can introduce 
distortions that hinder trade, the aggregate flows of investment on a regional basis, and ultimately connectivity. Similarly, market opening and restructuring in the backbone infrastructure sectors must have a parallel development (reciprocity) across countries. Otherwise, significant differences in market structures could hinder cross-border trade and connectivity. Regulatory and market structure harmonization, the elimination of trade-distorting inefficient national regulations, and regulatory co-operation to overcome domestic constraints on regulatory capacity and thus achieve regulatory effectiveness, are essential components of regional economic co-operation and connectivity.

\section{3}

\section{Summary}

After a decade of robust growth in the face of a very challenging global economic environment, Africa is at a crossroads. Policy decisions and actions taken today will have profound implications for the sustainability of the continent's economic renaissance and a strong bearing on whether it will succeed in making the transition from resource-driven to higher-value-added growth and thus place itself on a path similar to that of other successful regions such as developing Asia. Although this period of growth has given rise to increased optimism about Africa's economic prospects, the continent is facing several difficult challenges.

Many African countries continue to feature among the least competitive economies in the world. The emerging international experience indicates that regulatory reform and deregulation can make a substantive contribution towards resolving the continent's productivity and competitiveness dilemmas. Indeed, decentralized market-oriented decision-making that is freed from unnecessary regulatory control and that is energized by market incentives is the surest means of finding and implementing innovative solutions to problems posed in several sectors of Africa's economies.

Africa's business environment and competitiveness are adversely affected by: (i) inadequate and poor regional infrastructure networks that raise cross-border transaction costs; and (ii) weak institutional capacity. Increased regionalization could potentially address both of these challenges. Regional integration of regulation, combined with regionalization of regulated firms, could assist the countries of Africa in overcoming national limits in technical expertise, enhance national capacity to make credible commitments to stable regulatory policy, facilitate the introduction of competition into historically monopolized markets, improve the efficiency of infrastructure industries by allowing them to grow without respecting economically artificial national boundaries, and ultimately increase infrastructure investment.

\section{References}

African Development Bank (2006). 'Infrastructure Development and Regional Integration: Issues, Opportunities and Challenges'. Ministerial Round Table and High Level Seminars Jointly Organized with the UN Economic Commission for Africa, 16 May 2016, Ouagadougou, Burkina Faso.

Ajibewa, A. (2002). 'From Regional Security to Regional Integration in West Africa: Lessons from the ASEAN Experience'. Working Paper 5. London: Centre for Democracy and Development.

Aryeetey, E. (2001). 'Regional Integration in West Africa'. Working Paper 170. Paris: OECD Development Centre. 
Deutsche Bank (2013). 'Sub-Saharan Africa: A Bright Spot in Spite of Key Challenges'. Available at: https://www.dbresearch.com/PROD/DBR_INTERNET_EN-

PROD/PROD0000000000317226/Sub-

Saharan + Africa $\% 3 \mathrm{~A}+\mathrm{A}+$ bright + spot + in + spite + of + key + challenges.PDF

Devarajan, S., and W. Fengler (2013). 'Africa's Economic Boom: Why the Pessimists and the Optimists Are Both Right'. Foreign Affairs, May/June 2013 Issue. Available at: http://www.foreignaffairs.com/articles/139109/shantayanan-devarajan-and-wolfgangfengler/africas-economic-boom

Deloitte Touche Tohmatsu (2003). 'Harmonization of Telecommunications Policies in ECOWAS’. Project No: 7118448.

Dollar, D., T. Kleineberg, and A. Kraay (2013). 'Growth Still Is Good for the Poor'. Policy Research Working Paper 6568. Washington, DC: World Bank.

Ernst \& Young (2013). 'Ernst \& Young's Attractiveness Survey: Africa 2013'. Available at: http://www.ey.com/Publication/vwLUAssets/The_Africa_Attractiveness_Survey_2013/\$ FILE/Africa_Attractiveness_Survey_2013_AU1582.pdf

ESCAP (United Nations Economic and Social Commission for Asia and the Pacific) (2007). 'Toward an Asian Integrated Transport Network'. ST/ESCAP/2399. New York: United Nations ESCAP.

Foster, V., and C. Briceno-Garmendia (2010). 'Africa's Infrastructure-A Time for Transformation'. A Copublication of the Agence Française de Développement and the World Bank. Washington DC: World Bank.

Global Finance (2013). 'Best Countries for Doing Business 2013'. Available at: http://www.gfmag.com/component/content/article/119-economic-data/12525-bestcountries-for-doing-business-2013.html\#axzz2jiteBkth

Guasch, L.J., and P. Spiller (1999). Managing the Regulatory Process: Design, Concepts, Issues, and the Latin America and Caribbean Story. Washington, DC: World Bank.

InfoDev/ITU (International Telecommunications Union) (2006). 'Legal and Institutional Aspects of Regulation'. Module 6, ICT Regulation Toolkit. Available at: http://www.ictregulationtoolkit.org/en/Section.1254.html

Jacobs, S., and J. Astrakhan (2006). 'Bold and Sustainable Regulatory Reform: The Regulatory Guillotine in Three Transition and Developing Countries'. World Bank Conference Reforming the Business Environment: From Assessing Problems to Measuring Results, 29 Nov-1 Dec 2005, Cairo.

Kahn, A. (2004). Lessons from Deregulation. Washington, DC: AEI-Brookings Joint Center for Regulatory Studies.

Kessides, I., R. Noll, and N. Benjamin (2010). 'Regionalising Regulatory Reform in Developing Countries'. World Economics, 11(3): 79-108.

Kuroda, H. (2006). 'Infrastructure and Regional Cooperation'. Paper presented at the Annual Bank Conference on Development Economies, 29-30 May 2006, Tokyo.

Moreira, M. (2007). 'Trade Costs and the Economic Fundamentals of the Initiative for Integration of Regional Infrastructure in South America (IIRSA)'. INTAL-ITD Working Paper 30. Buenos Aires: IDB-INTAL.

Noll, R. (1997). 'International Regulatory Reform'. In P. Nivola (eds), Comparative Disadvantage? Social Regulations and the Global Economy. Washington, DC: Brookings Institution. 
Noll, R. (2000). 'Regulatory Reform and International Trade Policy'. In T. Ito and A. Krueger (eds), Deregulation and Interdependence in the Asia-Pacific Region. Chicago: University of Chicago Press.

Rose, N. (2013). 'Learning from the Past: Insights for the Regulation of Economic Activity'. Chapter in forthcoming National Bureau of Economic Research Book Economic Regulation and Its Reform: What Have We Learned?. Chicago: University of Chicago University Press. Paper currently available at: http://www.nber.org/chapters/c12564

Stern, J. (2000). 'Electricity and Telecommunications Regulatory Institutions in Small and Developing Countries'. Utilities Policy, 9(3): 131-57.

Stern, J., P. Domah, and M. Pollitt (2002). 'Modelling the Costs of Energy Regulation: Evidence of Human Resource Constraints in Developing Countries'. Regulation Initiative Working Paper 49. London: London Business School.

USAID/CARANA (2004) 'Impact Assessment: ECTEL States'. OECS/Telecommunications Liberalization Programme.

The Economist (2012). 'Doing Business 2012: Getting Better'. The Economist, 27 October 2012. Available at: http://www.economist.com/news/business/21565250-bad-rules-breedcorruption-cutting-them-costs-nothing-getting-better

World Bank (2013a). The Africa Competitiveness Report 2013. Washington, DC: World Bank.

World Bank (2013b). Doing Business 2014: Understanding Regulations for Small and Medium-Size Enterprises. Washington, DC: World Bank. 